\title{
RESEARCH
}

Open Access

\section{The value of restaging $C T$ following neoadjuvant chemotherapy for resectable gastric cancer. A population-based study}

\author{
Alina Desiree Sand $\varnothing^{1,2^{*}} \mathbb{D}$, Reidun Fougner ${ }^{3}$, Jon Erik Grønbech ${ }^{1,2}$ and Erling Audun Bringeland ${ }^{1,2}$
}

\begin{abstract}
Background: Response evaluation following neoadjuvant chemotherapy (NAC) in gastric cancer is debated. The aim of this study was to investigate the value of UICC-downstaging as mode of response evaluation following a MAGIC-style regimen of NAC.
\end{abstract}

Methods: Retrospective, population-based study on consecutive patients with resectable gastric adenocarcinoma receiving NAC from 2007 to 2016. CT-scan was obtained at diagnosis (rTNM) and repeated following NAC (yrTNM) to evaluate response in terms of downstaging. Further, yrTNM stage was crosstabulated to pathologic stage (ypTNM) to depict correlation between radiologic and pathologic assessment.

Results: Of 171 patients receiving NAC, 169 were available for response evaluation. For TNM-stages, 43\% responded, 50\% had stable disease and 7\% progressed at CT. Crosstabulating yrTNM stage to ypTNM stage, 24\% had concordant stages, with CT overstaging 38\% and understaging 38\% of the tumours, Cohen kappa $\mathrm{k}=0,06$ ( $95 \% \mathrm{Cl}$ 0.004-0.12). Similar patterns of discordance were found for T-stages and N-stages separately. For M-category, restaging $C T$ detected 12 patients with carcinomatosis, with an additional 14 diagnosed with carcinomatosis only at operation. No patient developed parenchymal or extra abdominal metastases, and none developed locally nonresectable tumour during delivery of NAC. Restaging $C T$ with response evaluation was not able to stratify patients into groups of different long-term survival rates based on response mode.

Conclusions: Routine CT-scan following NAC is of limited value. Accuracy of CT staging compared to final pathologic stage is poor, and radiologic downstaging as measure of response evaluation is unreliable and unable to discriminate long-term survival rates based on response mode.

Keywords: Gastric cancer, Response evaluation, Neoadjuvant chemotherapy, Downstaging

\footnotetext{
* Correspondence: alina.desiree.sando.klemmetvoll@stolav.no

'Department of Gastrointestinal Surgery, St. Olavs Hospital, Trondheim University Hospital, 7006 Trondheim, Norway

${ }^{2}$ Department of Cancer Research and Molecular Medicine, Norwegian University of Science and Technology, Trondheim, Norway

Full list of author information is available at the end of the article
}

(C) The Author(s). 2021 Open Access This article is licensed under a Creative Commons Attribution 4.0 International License, which permits use, sharing, adaptation, distribution and reproduction in any medium or format, as long as you give appropriate credit to the original author(s) and the source, provide a link to the Creative Commons licence, and indicate if changes were made. The images or other third party material in this article are included in the article's Creative Commons licence, unless indicated otherwise in a credit line to the material. If material is not included in the article's Creative Commons licence and your intended use is not permitted by statutory regulation or exceeds the permitted use, you will need to obtain permission directly from the copyright holder. To view a copy of this licence, visit http://creativecommons.org/licenses/by/4.0/ The Creative Commons Public Domain Dedication waiver (http://creativecommons.org/publicdomain/zero/1.0/) applies to the data made available in this article, unless otherwise stated in a credit line to the data. 


\section{Background}

Since the publication of the British MAGIC trial in 2006, perioperative chemotherapy has been standard of care in Europe for resectable gastric cancer [1-3]. The regimen was recently superseded by the German FLOT4 following a randomized controlled trail comparing the two head on, concluding with improved pathologic response and long-term survival rates for the latter [2, 4]. Evidence suggests a differential effectiveness of perioperative chemotherapy on clinicopathologic variables as stage, histological subtypes and genomic profile [2, 5-9]. For the MAGIC regimen, up to $15 \%$ experienced disease progression, even to metastatic disease, indicating that not all benefit from neoadjuvant chemotherapy (NAC) $[4,7,10]$. Still, NAC is persistently administered as a "one size fits all" treatment.

Two principally different approaches for evaluating tumour response following NAC are available. First is histologic criteria like the Becker tumour regression grade or the Mandard score [11, 12]. Second is response evaluation by standardized CT scans before and after chemotherapy, either as UICC-downstaging or by measuring downsizing with methods like RECIST (Response Evaluation Criteria in Solid Tumours) [13]. No consensus exists on the preferred method, and implications of findings are still debated [7, 14].

The aim of this study was to explore how standardized CT-scans perform when used to evaluate response following NAC in terms of UICC-downstaging and measure concordance between radiologic assigned stage (yrTNM) and pathologic stage (ypTNM) as a marker of the reliability of the radiologic downstaging.

\section{Material and methods}

\section{Study design}

The study design is a retrospective, population-based study from Central Norway. Since 2006, evaluation and treatment of gastric cancer was centralized to St. Olavs Hospital, the university hospital of the region, with a catchment area of 700.000 , constituting some $14 \%$ of the Norwegian population. All patients with histologically verified gastric adenocarcinoma from 1 January 2007 to 31 December 2016 were identified through the Norwegian Cancer Registry (NCR) and The Norwegian Patient Register (NPR). Individual electronic patient journals (EPJ) were reviewed to secure a complete registration of relevant clinical variables for 733 patients. Patients in a curative setting with tumours of true gastric or cardia types II/III location, receiving perioperative chemotherapy, were the objective for further study. Established criteria for perioperative chemotherapy were clinical stage Ib-III, age below 75 years, and WHO 0-1 performance status, leaving 171 to constitute the study cohort (Fig. 1). The study was approved by the Regional Ethics
Committee. The manuscript was prepared in accordance with the STROBE guidelines.

\section{Perioperative chemotherapy}

As part of national standard, a MAGIC style regimen of perioperative chemotherapy was introduced in 2007 for resectable gastric cancer at St. Olavs Hospital. Oral capecitabin $\left(x^{2} l o d a^{\circ}\right) 1250 \mathrm{mg} / \mathrm{m}^{2}$ was given for 21 days, i.v. oxaliplatin $130 \mathrm{mg} / \mathrm{m}^{2}$ or i.v. cisplatin $60 \mathrm{mg} / \mathrm{m}^{2}$ on day 1 , and i.v. epirubicin $50 \mathrm{mg} / \mathrm{m}^{2}$ on day 1 . The EOX/ ECX regimen was delivered with three cycles prior to surgery and three to follow for radically resected patients.

\section{Tumour staging and response evaluation}

All patients were discussed at multidisciplinary meetings following initial staging with $\mathrm{CT}$ and gastroscopy. In accordance with national guidelines endoscopic ultrasound, PET-CT or laparoscopy prior to NAC was not routinely used [15]. Radiologic staging was done with a multidetector CT (Siemens Somatotom Definition Flash or $\mathrm{AS}+$, with detector $128 \times 0.6$ ), with repeated imaging for restaging following NAC. The procedure was standardized and the protocol designed for optimal gastric distention [16, 17]. Following a fasting period of four hours, $20 \mathrm{mg}$ butylscopolamine bromide was administered i.v and $1 \mathrm{l}$ of tap water orally together with effervescent granules. Intravenous contrast was given as Omnipaque $350 \mathrm{mg} / \mathrm{ml}$ at a rate of $4 \mathrm{ml} / \mathrm{s}$, volume depending on the patient's weight $(120-180 \mathrm{ml})$. CT images were obtained after 45 and $70-75 \mathrm{~s}$. Images were reconstructed to series of 1.5 and $3 \mathrm{~mm}$ thin slices in the axial, coronal and sagittal planes. There was no use of three-dimensional rendering.

For study purposes, a senior gastro radiologist, blinded to final ypTN stage did the radiologic response evaluation. Disease stage at baseline and following NAC were set as follows: T1, invisible tumour or focal thickening of mucosal layer; $\mathrm{T} 2$, focal thickening of the gastric wall with smooth outer border; T3, diffuse or focal transmural thickening of the gastric wall with blurry border to periventricular fat; and T4, tumour infiltrating the serosal lining or other organs. Lymph nodes were considered malignant when short axis enlarged to $\geq 10 \mathrm{~mm}$ or showing a pathologic structure. M+ category was defined as malignant peritoneal deposits, paraaortic nodes or organ metastases. Radiologic downstaging as a measure of response was defined as a lowering of disease stage one or more tiers at $\mathrm{CT}$, disease progression as migration to a higher stage, otherwise judged as stable disease. The Union for International Cancer Control (UICC) and the American Joint Committee on Cancer (AJCC) TNM classification 7th. edition was used [18]. 


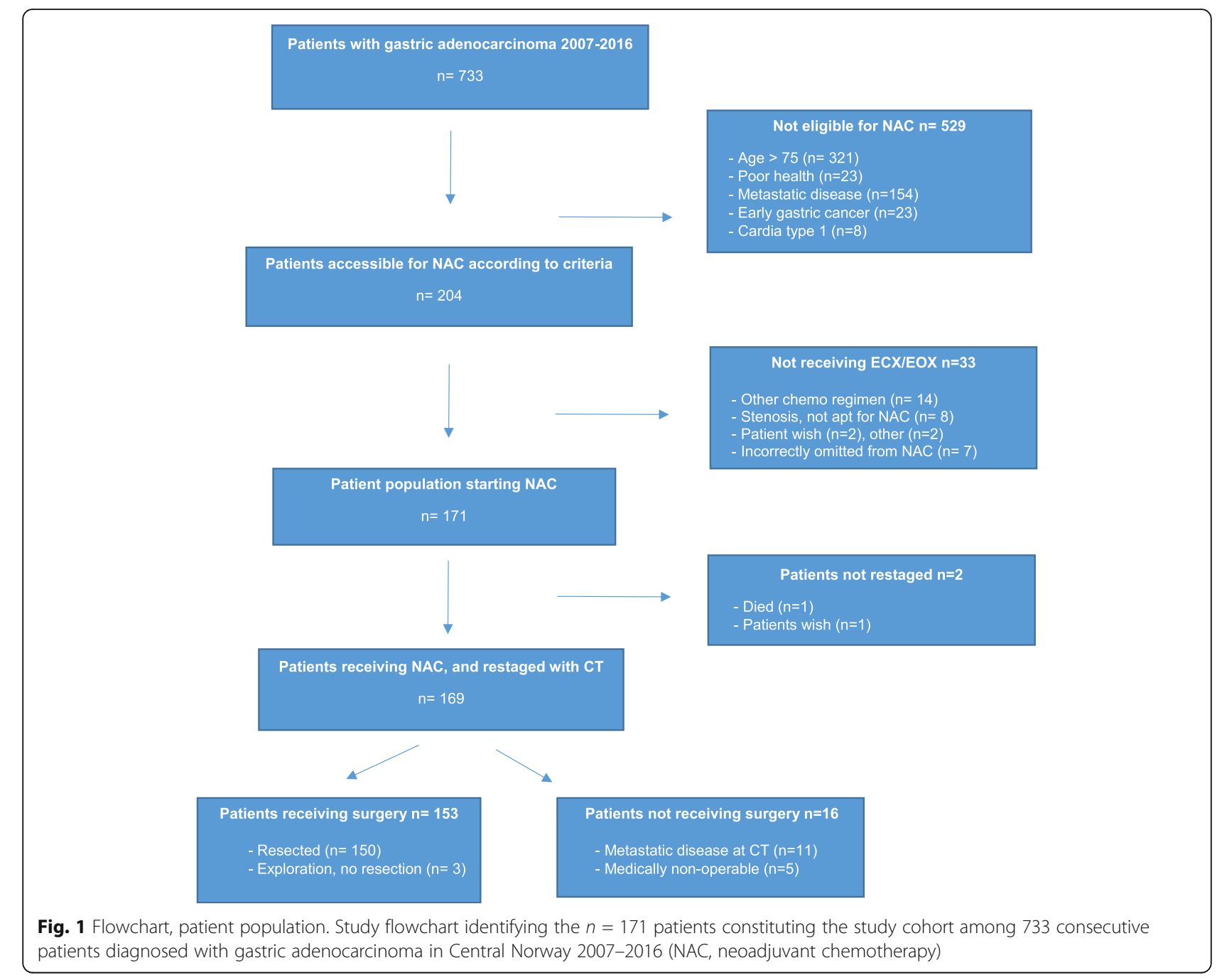

\section{Statistics}

Continuous variables are reported as mean (range). Categorical variables are crosstabulated and analysed using the $\chi^{2}$ test. Concordance was defined as proportion of stages coincident at the diagonal on crosstabulation. The Cohen kappa statistic was used to determine the correlation between radiologic yrTNM and pathologic ypTNM stages. Overall survival rates were analysed using the Kaplan-Meier method and compared by the log-rank test. Level of statistical significance was set at $p=0.05$. Analyses were done using IBM SPSS Statistics version 27.

\section{Results}

A total of 171 patients with mean age 63 years (range 27-77) started perioperative chemotherapy (Fig. 1). ECX was given to 57 (33\%) and EOX to $114(67 \%)$. Tolerability of NAC was on par with numbers reported by others $[2,3]$ with $145 / 171(85 \%)$ completing the three preoperative cycles and 32/171 (19\%) having one or more dose reductions.

\section{Radiologic response evaluation: $\mathrm{CT}$ stage at diagnosis} (rTNM) vs CT stage following NAC (yrTNM)

Two patients were unavailable for response evaluation, one died during NAC and one refused further imaging and treatment, leaving 169 patients to compare CT stage at diagnosis (rTNM) to CT stage following NAC (yrTNM). (Table 1, Fig. 2). For radiologic UICC-stage, $73 / 169$ patients (43\%) responded, $50 \%$ had stable disease and $7 \%$ had progression (Fig. 2). Only four patients were appraised as radiological complete responders. Of the $7 \%$ with progression, all had stage III disease at the outset, all progressed to peritoneal carcinomatosis and none developed parenchymatous organ metastases. Radiologic response crosstabulated on several clinical variables showed that gender, age, Lauren type or number of NAC cycles were not significantly related to response category. Tumour location and $\mathrm{T}$ stage had a significant bearing on response mode, accounted for by a lack of response for tumours of anatomic diffuse 
Table 1 Clinical variables for patients with resectable gastric cancer 2007-2016 receiving neoadjuvant chemotherapy (NAC). Response was evaluated by TNM downstaging at repeated CT-scans, $n=169$ (\%)

\begin{tabular}{|c|c|c|c|c|c|}
\hline & Total & Response & Stable disease & Progression & $p$ value* \\
\hline Age category & & & & & 0.55 \\
\hline$<60$ years & $48(28 \%)$ & $19(40 \%)$ & $23(48 \%)$ & $6(13 \%)$ & \\
\hline 60-70 years & $76(45 \%)$ & $34(45 \%)$ & $38(50 \%)$ & $4(5 \%)$ & \\
\hline$>70$ years & $45(27 \%)$ & $20(44 \%)$ & $23(51 \%)$ & $2(4 \%)$ & \\
\hline Gender & & & & & 0.47 \\
\hline Male & $118(70 \%)$ & $54(46 \%)$ & 55 (47\%) & $9(8 \%)$ & \\
\hline Female & $51(30 \%)$ & 19 (37\%) & $29(57 \%)$ & $3(6 \%)$ & \\
\hline Tumour location & & & & & 0.03 \\
\hline Cardia & 65 (38\%) & $32(49 \%)$ & $29(45 \%)$ & $4(6 \%)$ & \\
\hline Corpus & 32 (19\%) & 19 (59\%) & $12(38 \%)$ & $1(3 \%)$ & \\
\hline Antrum & $51(30 \%)$ & 19 (37\%) & 30 (59\%) & $2(4 \%)$ & \\
\hline Diffuse & $21(12 \%)$ & $3(14 \%)$ & $13(62 \%)$ & $5(24 \%)$ & \\
\hline Disease stage ${ }^{* *}$ & & & & & $<0.01$ \\
\hline Stage $1 b$ & $14(8 \%)$ & $5(36 \%)$ & $9(64 \%)$ & 0 & \\
\hline Stage Ila/b & $54(32 \%)$ & $15(28 \%)$ & $39(72 \%)$ & 0 & \\
\hline Stage IIla & 32 (19\%) & $18(56 \%)$ & $13(41 \%)$ & $1(3 \%)$ & \\
\hline Stage IIIb & $42(25 \%)$ & $20(48 \%)$ & $17(41 \%)$ & $5(12 \%)$ & \\
\hline Stage IIIC & $27(16 \%)$ & $15(56 \%)$ & $6(22 \%)$ & $6(22 \%)$ & \\
\hline$T$-stage * $^{* *}$ & & & & & 0.04 \\
\hline $\mathrm{T} 2$ & $22(13 \%)$ & $11(50 \%)$ & $11(50 \%)$ & 0 & \\
\hline T3 & $33(20 \%)$ & $11(33 \%)$ & $22(67 \%)$ & 0 & \\
\hline $\mathrm{T} 4 \mathrm{a} / \mathrm{b}$ & 114 (67\%) & $51(45 \%)$ & $51(45 \%)$ & $12(11 \%)$ & \\
\hline$N$-stage ${ }^{* *}$ & & & & & $<0.01$ \\
\hline NO & 53 (31\%) & 10 (19\%) & $41(77 \%)$ & $2(4 \%)$ & \\
\hline $\mathrm{N} 1$ & $50(30 \%)$ & $24(48 \%)$ & $24(48 \%)$ & $2(4 \%)$ & \\
\hline N2 & $51(30 \%)$ & $33(65 \%)$ & $15(29 \%)$ & $3(6 \%)$ & \\
\hline N3 & $15(9 \%)$ & $6(40 \%)$ & $4(27 \%)$ & $5(33 \%)$ & \\
\hline Lauren classification ${ }^{* * *}$ & & & & & 0.79 \\
\hline Diffuse & $68(40 \%)$ & $26(38 \%)$ & 37 (54\%) & $5(7 \%)$ & \\
\hline Intestinal & $73(43 \%)$ & $33(45 \%)$ & $34(47 \%)$ & $6(8 \%)$ & \\
\hline Mixed & $27(16 \%)$ & $14(52 \%)$ & $12(44 \%)$ & $1(4 \%)$ & \\
\hline Number of cycles delivered & & & & & 0.41 \\
\hline$<3$ & $24(14 \%)$ & $12(50 \%)$ & $11(46 \%)$ & $1(4 \%)$ & \\
\hline 3 & $145(86 \%)$ & $61(42 \%)$ & $73(50 \%)$ & $11(8 \%)$ & \\
\hline
\end{tabular}

*Chi-square monovariable analysis

**Radiological staging at time of diagnosis (rTNM)

***One patient with unspecified Lauren category omitted

location and T4 cancers, respectively (Table 1 ). Assessing $\mathrm{T}$-stages isolated, none of the tumours migrated to a higher category at CT, 121/169 (72\%) were appraised as stable and 48 (28\%) migrated to a lower Tcategory following NAC. Of these, 33 (69\%) migrated only one tier down. Assessing N-category, 49/169 (29\%) migrated to a lower category, of whom 40 from
$\mathrm{N} 2$ to N1. Only one patient migrated to a higher Ncategory, but with concomitant progression to $\mathrm{M}+$ disease. The remaining 119 (70\%) were judged to have a stable Ncategory at CT. An isolated change of T or N-category following NAC should not be interpreted as formal response or progression, as response evaluation in this study used the composite UICC TNM-stage. 


\begin{tabular}{|c|c|c|c|c|c|c|c|c|c|c|c|}
\hline \multirow{9}{*}{$\begin{array}{l}\text { rTNM; } \\
\text { radiologic } \\
\text { baseline } \\
\text { stage }\end{array}$} & \multicolumn{11}{|c|}{ yrTNM; radiologic stage after NAC } \\
\hline & STAGE & 0 & IA & $\mathrm{IB}$ & IIA & IIB & IIIA & IIIB & IIIC & IV & Total \\
\hline & IB & 3 & 2 & 9 & 0 & 0 & 0 & 0 & 0 & 0 & 14 \\
\hline & IIA & 0 & 0 & 6 & 16 & 0 & 0 & 0 & 0 & 0 & 22 \\
\hline & IIB & 1 & 0 & 3 & 5 & 23 & 0 & 0 & 0 & 0 & 32 \\
\hline & IIIA & 0 & 0 & 5 & 3 & 10 & 13 & 0 & 0 & 1 & 32 \\
\hline & IIIB & 0 & 0 & 0 & 0 & 10 & 10 & 17 & 0 & 5 & 42 \\
\hline & IIIC & 0 & 0 & 0 & 0 & 4 & 3 & 8 & 6 & 6 & 27 \\
\hline & Total & 4 & 2 & 23 & 24 & 47 & 26 & 25 & 6 & 12 & 169 \\
\hline
\end{tabular}

Fig. 2 Radiologic response evaluation. Crosstabulation of CT-stage at diagnosis (rTNM) vs CT-stage following neoadjuvant chemotherapy (yrTNM), $n=169$. Numbers on stage migration express response/progression. Green = downstaging/response, yellow = stable stage, red

= upstaging/progression

Inter procedure reliability, CT stage after NAC (yrTNM) vs pathologic stage after surgery (ypTNM)

Of the 169 patients restaged by CT following NAC, 12 were diagnosed with $\mathrm{M}+$, and an additional five with $\mathrm{M} 0$ were deemed unfit for surgery. A total of 153/169 (91\%) were referred for surgery, including one patient diagnosed with $\mathrm{M}+$ at $\mathrm{CT}$ evaluation. Perioperatively, 14 were diagnosed with carcinomatosis unrecognized at restaging CT, with 11 of these receiving resection (Fig. 1). This implies a CT sensitivity of $46 \%$ and specificity of $100 \%$ in detecting peritoneal carcinomatosis. At histologic examination of resected specimen, one patient was further diagnosed with tumour cells in the omentum $(\mathrm{M}+)$, not acknowledged at CT or at operation. Of note, none of the operated patients had a locally non-resectable tumour. Altogether, 164 patients had an ypTNM-stage assigned to be compared to the yrTNM-stage. Only 39/164 (24\%) had concordant stages, $38 \%$ overstaged and $38 \%$ understaged at CT, $\mathrm{k}=0.06$ (95\% CI 0.004-0.12). CT found complete radiologic response in four patients, compared to $15 / 164$ (9\%) with histologic complete response (Fig. 3a). Since 19/ 169 (11\%) were not resected, the number of ypT- and ypN-stages was correspondingly lowered. For T-stage, CT was concordant in 50/150 (33\%), overstaged $46 \%$ and understaged 21\% (Fig. 3b), $k=0.1$ (95\% CI 0.01-0.18). Overstaging by CT following NAC was particularly common, staging only six tumours as T0 compared to 14 histologic T0 cancers. For N stage, CT was concordant for $59 / 150$ patients $(39 \%)$, overstaging $23 \%$ and understaging 37\% (Fig. 3c), $k=0.097$ (95\% CI 0.02-0.18). Most cases of misclassification were due to understaging with no patients staged to yrN3, whereas the pathologic report assigned 25 patients to $\mathrm{N} 3$ status.

The discriminating ability of radiologic response mode on long-term survival rates.

Long-term survival rates for all patients stratified on response mode are depicted in Fig. 4. As expected, patients with progressive disease at CT had a substantially inferior survival since all were allocated to this group due to metastatic disease at restaging CT. No significant difference was found in long-term survival rates for patients with stable disease compared to those judged to be responders at restaging CT, $\log \operatorname{rank} p=0.237$ (Fig. 4).

\section{Discussion}

Two principally different approaches for evaluating tumour response following NAC are available. Histologic criteria such as the Becker tumour regression grade [12] or the Mandard score $[11,19]$ both restricted to evaluate the resected specimen or radiologic methods as UICCdownstaging [18] or RECIST-downsizing [13] using metrics to tumour and lymph nodes. There is no consensus on preferred approach, and clinical implications of findings are still discussed [7].

An advantage of radiologic response is the possibility to include all patients receiving NAC and not by virtue exclude those not resected. Further, radiologic methods include $\mathrm{N}$-stage and $\mathrm{M}$-stage in the evaluation, with histopathologic methods restricted to evaluation of the main tumour [11, 12]. For downsizing, RECIST compares unidimensional measurements of target lesions before and after NAC, whereas nontarget lesions are assessed as present or absent [13]. The 2009 revised version, based on data from more than 16 trials, had no gastric cancer patients included [20]. The gastric primary is counted as a non-target lesion, whereas lymph nodes are required to be $\geq 15$ $\mathrm{mm}$ at diagnoses to be classified as a nodal target lesion. Applying this to the present study would leave only 18 patients with a nodal target lesion to measure (data not shown). Hence, potential advantages can be envisaged moving strategy from RECIST and downsizing to radiologic TNM downstaging. First, evaluation is not limited to metric measurements but is able to grasp a wider picture by including both $\mathrm{T}-, \mathrm{N}$ - and $\mathrm{M}$-categories, with the added value of using a common language for radiologic evaluation and pathologic examination of the specimen [21]. Second, long-term survival rates are prognosticated by UICC stages, and 
a

\begin{tabular}{|c|c|c|c|c|c|c|c|c|c|c|c|}
\hline \multirow{12}{*}{$\begin{array}{l} \\
\text { yrTNM; } \\
\text { radiologic } \\
\text { stage after } \\
\text { NAC }\end{array}$} & \multicolumn{11}{|c|}{ ypTNM; pathologic stage after NAC } \\
\hline & STAGE & 0 & IA & IB & $\| A$ & IIB & IIIA & IIIB & IIIC & IV & Total \\
\hline & 0 & 1 & 1 & 1 & 0 & 0 & 1 & 0 & 0 & 0 & 4 \\
\hline & IA & 0 & 2 & 0 & 0 & 0 & 0 & 0 & 0 & 0 & 2 \\
\hline & IB & 8 & 3 & 1 & 4 & 1 & 3 & 2 & 1 & 0 & 23 \\
\hline & IIA & 1 & 3 & 1 & 6 & 4 & 2 & 2 & 2 & 2 & 23 \\
\hline & IIB & 2 & 3 & 2 & 11 & 9 & 5 & 6 & 5 & 3 & 46 \\
\hline & IIIA & 1 & 0 & 1 & 3 & 3 & 6 & 2 & 5 & 4 & 25 \\
\hline & IIIB & 1 & 1 & 0 & 5 & 3 & 7 & 2 & 1 & 4 & 24 \\
\hline & IIIC & 1 & 0 & 0 & 1 & 0 & 2 & 0 & 0 & 1 & 5 \\
\hline & IV & 0 & 0 & 0 & 0 & 0 & 0 & 0 & 0 & 12 & 12 \\
\hline & Total & 15 & 13 & 6 & 30 & 20 & 26 & 14 & 14 & 26 & 164 \\
\hline
\end{tabular}

b

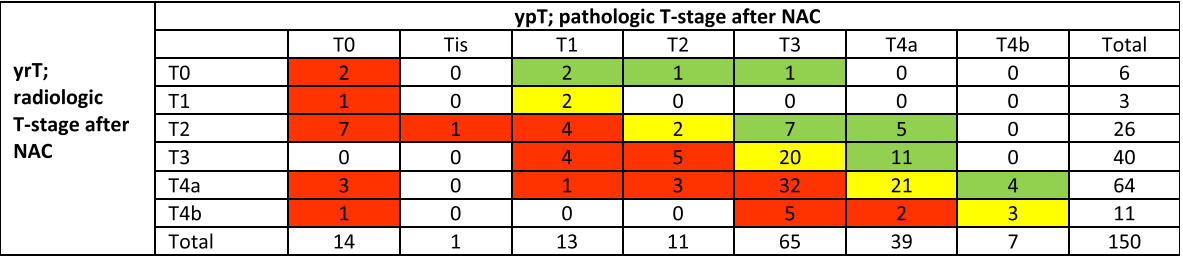

C

\begin{tabular}{|l|l|c|c|c|c|c|c|}
\hline \multirow{3}{*}{$\begin{array}{l}\text { yrN; } \\
\text { radiolo }\end{array}$} & \multicolumn{7}{|c|}{ ypN; pathologic N-stage after NAC } \\
\cline { 2 - 8 } gic & & N0 & N1 & N2 & N3 & NX & Tot. \\
\cline { 2 - 8 } $\begin{array}{l}\text { N- } \\
\text { stage } \\
\text { after } \\
\text { NAC }\end{array}$ & N1 & 43 & 12 & 8 & 10 & 1 & 74 \\
\cline { 2 - 8 } & $\mathrm{N} 2$ & 12 & 5 & 10 & 4 & 0 & 31 \\
\cline { 2 - 8 } & N3 & 0 & 0 & 0 & 0 & 0 & 0 \\
\hline
\end{tabular}

Fig. 3 Correlation between radiologic and pathologic UICC TNM-stages a) CT-stage following NAC (yrTNM) vs definitive pathologic stage (ypTNM), $n=164$. b) CT T-stage following NAC (yrT) vs definitive pathologic T-stage (ypT), $n=150$. c) CT N-stage following NAC (yrN) vs definitive pathologic $N$-stage (ypN), $n=150$. Green = understaging, yellow = concordant staging, red = overstaging

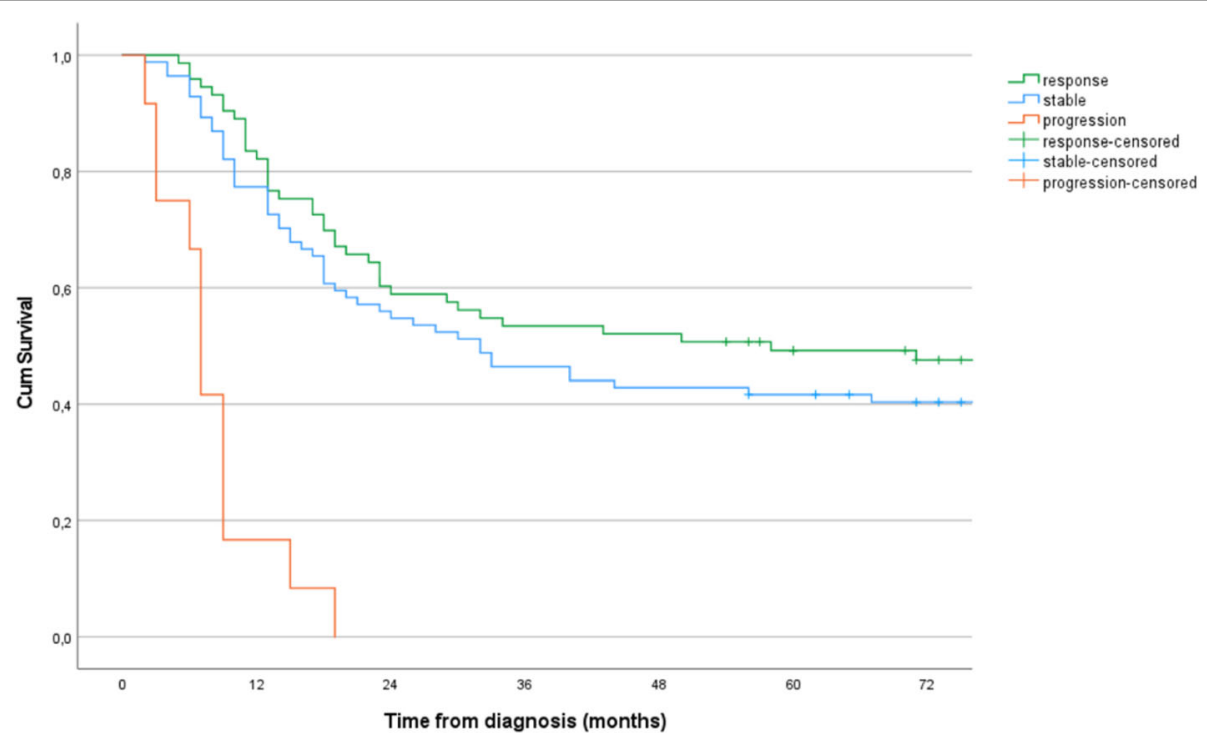

Fig. 4 Kaplan-Meier plot of estimated overall survival according to response group. Response assigned by comparing radiologic stage following neoadjuvant chemotherapy (yrTNM) to radiologic stage at baseline (rTNM) for $n=169$ patients with true gastric cancer 
downstaging following NAC may intuitively be expected to translate into improved long-term survival rates. Tumour size alone or downsizing by metrics is less correlated to survival rates [22, 23].

The findings of this study, however, suggest that CT downstaging does not serve as an adequate tool in evaluating response to NAC. CT assigned stages following NAC are unreliable, and CT-response mode is unable to discriminate strata of significant different long-term survival rates. First, half of the patients developing carcinomatosis during NAC had the progression undetected at restaging CT. Second, any acknowledged progression was only to metastatic disease $\left(M_{+}\right)$, with no tumours deemed to have progression restricted to T-category. Reason suggests otherwise, as illustrated by comparing baseline rT-stage to ypT-stage, identifying 15 patients with tumours judged to migrate to a higher T-stage (data not shown). Along the same reasoning, CT following NAC classified only one patient progressing to a higher $\mathrm{N}$-stage from baseline $\mathrm{CT}$, whereas radiologic $\mathrm{N}$ stage at baseline compared to pathologic $\mathrm{N}$-stage suggested that 43 patients progressed to a higher $\mathrm{N}$-stage (data not shown). Third, CT downstaging failed the objective of assigning patients to groups with different long-term survival rates based on response mode. As expected, patients progressing on NAC demonstrated inferior survival since the group was constituted by patients with metastatic disease at restaging $\mathrm{CT}$, but survival rates for responders and patients with stable disease showed no significant difference (Fig. 4).

An Achilles heel of radiologic response evaluation is the need to accurately stage patients, both at baseline and following NAC. In a setting with upfront surgery, the radiologic concordance comparing baseline CT to pathologic stage lies within $69-88 \%$ for T-stage [24-26] and $51-71 \%$ for N-stage [27], the latter further obscured by a lack of agreement on cut-off size for nodes to be deemed infiltrated [28]. Following NAC results deteriorate. Studies report a concordance between yrT and ypT ranging from $33-57 \%[24,29,30]$. Chemotherapyinduced inflammation and oedema imped the evaluation of tumour depth invasion [31], and CT has a low ability to differentiate chemotherapy induced fibrosis from vital tumour tissue, leading to an overstaging of T-category [24]. For N-stages, concordance between yrN and ypN is reported down at $37-51 \%[24,29,30]$, which is unfortunate since pathologic lymph node status following NAC $(\mathrm{ypN})$ is considered a main determinant for long-term survival in gastric cancer [32].

In the present paper, concordance between radiologic stage and histologic stage following NAC is in the lower range, for $\mathrm{T}$-stages at $33 \%$, for $\mathrm{N}$-stages at $40 \%$. However, even more informative is the correlation using the Cohen kappa statistic, although often not provided [24,
29, 30]. This quantification adjusts for concordance by chance and returns a lower but more realistic number on how the two methods of staging compare. By no doubt, response evaluation by CT downstaging is unreliable and to some extent overstates T-stage and understates $\mathrm{N}$ stage by two or more tiers. Correlation as seen in this paper, with kappa statistics at or below 0.1 both for the UICC T-, $\mathrm{N}$ - and composite TNM-stages, is rated as very poor [33]. Of further note is a low sensitivity for CT to detect carcinomatosis [34]. In the present paper, restaging CT identified carcinomatosis in 12 of 169 patients, whereas an additional 14 patients had carcinomatosis at operation. All patients progressing to metastatic disease did so from advanced disease stages at the outset. As laparoscopy has a better sensitivity for detecting peritoneal metastases [34], guidelines today recommend this when facing advanced disease in a curative setting [1], further limiting the role of restaging $\mathrm{CT}$ in patients following NAC.

A further key point is that CT following NAC did not detect any deeply located parenchymal or extraabdominal metastases that would have gone undetected by surgical exploration. Further, no patient was denied surgery following tumour progression to nonresectability, and none of the patients explored were found to have locally non-resectable tumours. Rather, the low accuracy of CT staging could misguide decision making and contribute unjustified to deny a patient surgery. In a frail patient with a large cardia tumour and lack of downstaging, risky surgery could be cancelled. However, as seen from Fig. 3b, some yrT3 or yrT4 cancers are found to be ypT0-2. These observations are in line with findings in a similar, recently published study from the Netherlands [35].

A strength of the present study is that it is populationbased with no selection bias. Multiple factors may, however, affect the quality and accuracy of the CT response evaluation. It is considered favourable that all CT examinations were performed at the same institution, using a standardized protocol. CT slice thickness was set at 1.5-3 $\mathrm{mm}$, whereas other studies often report slice thickness of $>5-7 \mathrm{~mm}$, which is not up to standards of current CTtechnology $[25,36]$. A limitation of the study is its retrospective nature and that a single gastro-radiologist performed the radiological response evaluation. Although securing a consistent evaluation of the CT scans, assessing inter-observer agreement is rendered impossible.

\section{Conclusion}

No consensus exists on how to perform response evaluation following neoadjuvant chemotherapy (NAC) for upfront resectable gastric cancer. The RECIST criteria using unidimensional measures of target lesions are not validated for gastric cancer. Based on data from a 10-year experience, we conclude that CT-scan with radiologic UICC 
restaging following NAC is not suited for response evaluation either. Accuracy of such staging compared to final pathologic stage is poor and radiologic downstaging as measure of response evaluation unreliable. Further, CT following NAC had a limited value in surgical decision making as no patient developed locally non-resectable tumour or deep organ metastases and selective use of diagnostic laparoscopy in patients with advanced localized disease at the outset will better identify patients progressing to peritoneal carcinomatosis.

\section{Abbreviations}

NAC: Neoadjuvant chemotherapy; UICC: International Union Against Cancer; AJCC: American Joint Committee on Cancer; TNM: Tumour (T), nodes ( $N$ ), and metastases (M); rTMN: Radiologic TNM at diagnosis; yrTNM: Radiologic TNM after neoadjuvant treatment; ypTNM: Pathologic TNM after neoadjuvant treatment; RECIST: Response Evaluation Criteria in Solid Tumours; NCR: Norwegian Cancer Registry (NCR); NPR: The Norwegian Patient Register; EPJ: Individual electronic patient journals

\section{Acknowledgements}

None

\section{Disclaimer}

The study has used data from the Cancer Registry of Norway. The interpretation and reporting of these data are the sole responsibility of the authors, and no endorsement by the Cancer Registry of Norway is intended nor should be inferred. Data from the Norwegian Patient Register has been used in this publication. The interpretation and reporting of these data are the sole responsibility of the authors, and no endorsement by the Norwegian Patient Register is intended nor should be inferred.

\section{Authors' contributions}

E.A Bringeland and J.E Grønbech conceived the idea. A.D Sandø, E.A Bringeland, R. Fougner and J.E Grønbech designed the work and obtained the data. A.D Sandø and E.A Bringeland analysed and interpreted the data. A.D. Sandø wrote the manuscript and prepared the figures and tables. E.A. Bringeland, J.E Grønbech and R.Fougner critically revised the manuscript. All authors are accountable for the contents of this work. All authors read and approved the final manuscript.

\section{Funding}

This research was supported by the Norwegian Cancer Fund, FFU (Joint Research Committee St. Olavs Hospital, Norway) and the Department of Surgery, St. Olavs Hospital, Trondheim University Hospital. The funders had no role in the study design, data collection and analysis, or preparation of the manuscript.

\section{Availability of data and materials}

The datasets generated and analysed during the current study are not publicly available due to hospital policy but are available from the corresponding author on reasonable request.

\section{Declarations}

\section{Ethics approval and consent to participate}

The study was approved by the Norwegian Regional Ethics Committee (case number 2016/2173).

\section{Consent for publication}

Not applicable

\section{Competing interests}

All authors declare that they have no competing interests.

\section{Author details}

'Department of Gastrointestinal Surgery, St. Olavs Hospital, Trondheim University Hospital, 7006 Trondheim, Norway. ${ }^{2}$ Department of Cancer
Research and Molecular Medicine, Norwegian University of Science and Technology, Trondheim, Norway. ${ }^{3}$ Department of Radiology St. Olavs Hospital, Trondheim University Hospital, Trondheim, Norway.

Received: 3 May 2021 Accepted: 22 June 2021

Published online: 13 July 2021

\section{References}

1. Smyth EC, Verheij M, Allum W, Cunningham D, Cervantes A, Arnold D, et al. Gastric cancer: ESMO Clinical Practice Guidelines for diagnosis, treatment and follow-up. Ann Oncol. 2016;27(suppl 5):v38-49. https://doi.org/10.1 093/annonc/mdw350

2. Al-Batran $\mathrm{SE}$, et al. Perioperative chemotherapy with fluorouracil plus leucovorin, oxaliplatin, and docetaxel versus fluorouracil or capecitabine plus cisplatin and epirubicin for locally advanced, resectable gastric or gastro-oesophageal junction adenocarcinoma (FLOT4): a randomised, phase 2/3 trial. Lancet. 2019;393(10184):1948-57. https://doi.org/10.1016/50140-673 6(18)32557-1.

3. Cunningham D, Allum WH, Stenning SP, Thompson JN, van de Velde CJH, Nicolson $\mathrm{M}$, et al. Perioperative chemotherapy versus surgery alone for resectable gastroesophageal cancer. N Engl J Med. 2006;355(1):11-20. https://doi.org/10.1056/NEJMoa055531.

4. Al-Batran SE, et al. Histopathological regression after neoadjuvant docetaxel, oxaliplatin, fluorouracil, and leucovorin versus epirubicin, cisplatin, and fluorouracil or capecitabine in patients with resectable gastric or gastro-oesophageal junction adenocarcinoma (FLOT4-AIO): results from the phase 2 part of a multicentre, open-label, randomised phase 2/3 trial. Lancet Oncol. 2016;17(12):1697-708. https://doi.org/10.1 016/S1470-2045(16)30531-9.

5. Polom K, Marano L, Marrelli D, de Luca R, Roviello G, Savelli V, et al. Metaanalysis of microsatellite instability in relation to clinicopathological characteristics and overall survival in gastric cancer. Br J Surg. 2018;105(3): 159-67. https://doi.org/10.1002/bjs.10663.

6. Jimenez Fonseca $\mathrm{P}$, et al. Lauren subtypes of advanced gastric cancer influence survival and response to chemotherapy: real-world data from the AGAMENON National Cancer Registry. Br J Cancer. 2017;117(6):775-82. https://doi.org/10.1038/bjc.2017.245.

7. Smyth EC, Wotherspoon A, Peckitt C, Gonzalez D, Hulkki-Wilson S, Eltahir Z, et al. Mismatch repair deficiency, microsatellite instability, and survival: an exploratory analysis of the Medical Research Council Adjuvant Gastric Infusional Chemotherapy (MAGIC) trial. JAMA Oncol. 2017;3(9):1197-203. https://doi.org/10.1001/jamaoncol.2016.6762.

8. Messager M, Lefevre JH, Pichot-Delahaye V, Souadka A, Piessen G, Mariette C, et al. The impact of perioperative chemotherapy on survival in patients with gastric signet ring cell adenocarcinoma: a multicenter comparative study. Ann Surg. 2011;254(5):684-93; discussion 693. https://doi.org/10.1097/ SLA.0b013e3182352647.

9. Jiang L, Ma Z, Ye X, Kang W, Yu J. Clinicopathological factors affecting the effect of neoadjuvant chemotherapy in patients with gastric cancer. World J Surg Oncol. 2021;19(1):44. https://doi.org/10.11 86/s12957-021-02157-x.

10. Reddavid R, Sofia S, Chiaro P, Colli F, Trapani R, Esposito L, et al. Neoadjuvant chemotherapy for gastric cancer. Is it a must or a fake? World J Gastroenterol. 2018;24(2):274-89. https://doi.org/10.3748/wjg. V24.i2.274.

11. Mandard AM, Dalibard F, Mandard JC, Marnay J, Henry-Amar M, Petiot JF, et al. Pathologic assessment of tumor regression after preoperative chemoradiotherapy of esophageal carcinoma. Clinicopathologic correlations. Cancer. 1994;73(11):2680-6. https://doi.org/10.1002/1097-0142 (19940601)73:11<2680::aid-cncr2820731105>3.0.co;2-c.

12. Becker K, Mueller JD, Schulmacher C, Ott K, Fink U, Busch R, et al. Histomorphology and grading of regression in gastric carcinoma treated with neoadjuvant chemotherapy. Cancer. 2003;98(7):1521-30. https://doi. org/10.1002/cncr.11660.

13. Eisenhauer EA, Therasse P, Bogaerts J, Schwartz LH, Sargent D, Ford R, et al. New response evaluation criteria in solid tumours: Revised RECIST guideline (version 1.1). Eur J Cancer. 2009;45(2):228-47. https://doi.org/10.1016/j.ejca.2 008.10.026.

14. Klevebro F, et al. Relevant issues in tumor regression grading of histopathological response to neoadjuvant treatment in 
adenocarcinomas of the esophagus and gastroesophageal junction. Dis Esophagus. 2020;33(6):1-6.

15. National Supervisor. 2018 [cited 2021 01.02]; Available from: https:/www. helsedirektoratet.no/retningslinjer/kreft-i-magesekken-handlingsprogram/ Kreft\%20i\%20magesekken\%20(ventrikkelkreft)\%20\%E2\%80\%93\%20Nasjona It\%20handlingsprogram\%20med\%20retningslinjer\%20for\%20diagnostikk,\%2 Obehandling\%20og\%20oppf\%C3\%B8lging.pdf/_/attachment/inline/131381 dd-0319-4a84-9370-9434f00a69fb:78f40a84df0f8468d489da0b49ba23274 6b86ef5/Kreft\%20i\%20magesekken\%20(ventrikkelkreft)\%20\%E2\%80\%93\%2 0Nasjonalt\%20handlingsprogram\%20med\%20retningslinjer\%20for\%20dia gnostikk,\%20behandling\%20og\%20oppf\%C3\%B8lging.pdf.

16. Shimizu K, Ito K, Matsunaga N, Shimizu A, Kawakami Y. Diagnosis of gastric cancer with MDCT using the water-filling method and multiplanar reconstruction: CT-histologic correlation. AJR Am J Roentgenol. 2005;185(5): 1152-8. https://doi.org/10.2214/AJR.04.0651.

17. Wei WZ, Yu JP, Li J, Liu CS, Zheng XH. Evaluation of contrast-enhanced helical hydro-CT in staging gastric cancer. World J Gastroenterol. 2005; 11(29):4592-5. https://doi.org/10.3748/wjg.v11.i29.4592.

18. TNM. 2021 [cited 2021 29.01.2021]; Available from: http://old.uicc.org/templa tes/uicc/pdf/tnm/091209_tnm_7th_edition_summary.pdf.

19. Langer $R$, Becker $K$. Tumor regression grading of gastrointestinal cancers after neoadjuvant therapy. Virchows Arch. 2018;472(2):175-86. https://doi. org/10.1007/s00428-017-2232-x.

20. Fuse N, Nagahisa-Oku E, Doi T, Sasaki T, Nomura S, Kojima T, et al. Effect of RECIST revision on classification of target lesions and overall response in advanced gastric cancer patients. Gastric Cancer. 2013;16(3):324-8. https:/ doi.org/10.1007/s10120-012-0187-9.

21. UICC, TNM classification of Malignant Tumoures 7 th ed. 2010

22. Bringeland EA, Wasmuth $\mathrm{HH}$, Gronbech JE. Perioperative chemotherapy for resectable gastric cancer - what is the evidence? Scand I Gastroenterol. 2017;52(6-7):647-53. https://doi.org/10.1080/00365521.2017.1293727.

23. Mansour JC, Schwarz RE. Pathologic response to preoperative therapy: does it mean what we think it means? Ann Surg Oncol. 2009;16(6):1465-79. https://doi.org/10.1245/s10434-009-0374-z

24. Park SR, Lee JS, Kim CG, Kim HK, Kook MC, Kim YW, et al. Endoscopic ultrasound and computed tomography in restaging and predicting prognosis after neoadjuvant chemotherapy in patients with locally advanced gastric cancer. Cancer. 2008;112(11):2368-76. https://doi.org/10.1 $002 /$ cncr.23483.

25. Kwee RM, Kwee TC. Imaging in local staging of gastric cancer: a systematic review. J Clin Oncol. 2007;25(15):2107-16. https://doi.org/10.1200/JCO.2006. 09.5224.

26. Yan C, Zhu ZG, Yan M, Zhang H, Pan ZL, Chen J, et al. Value of multidetector-row computed tomography in the preoperative $\mathrm{T}$ and $\mathrm{N}$ staging of gastric carcinoma: a large-scale Chinese study. J Surg Oncol. 2009;100(3):205-14. https://doi.org/10.1002/jso.21316.

27. Kwee RM, Kwee TC. Imaging in assessing lymph node status in gastric cancer. Gastric Cancer. 2009;12(1):6-22. https://doi.org/10.1007/s10120-0080492-5.

28. Saito T, Kurokawa Y, Takiguchi S, Miyazaki Y, Takahashi T, Yamasaki M, et al. Accuracy of multidetector-row $\mathrm{CT}$ in diagnosing lymph node metastasis in patients with gastric cancer. Eur Radiol. 2015;25(2):368-74. https://doi.org/1 0.1007/s00330-014-3373-9.

29. Lee SM, Kim SH, Lee JM, Im SA, Bang YJ, Kim WH, et al. Usefulness of CT volumetry for primary gastric lesions in predicting pathologic response to neoadjuvant chemotherapy in advanced gastric cancer. Abdom Imaging. 2009;34(4):430-40. https://doi.org/10.1007/s00261-008-9420-8.

30. Yoshikawa T, et al. Accuracy of CT staging of locally advanced gastric cancer after neoadjuvant chemotherapy: cohort evaluation within a randomized phase II study. Ann Surg Oncol. 2014;21(Suppl 3):S385-9.

31. Achilli $P$, de Martini $P$, Ceresoli M, Mari GM, Costanzi A, Maggioni $D$, et al. Tumor response evaluation after neoadjuvant chemotherapy in locally advanced gastric adenocarcinoma: a prospective, multi-center cohort study. J Gastrointest Oncol. 2017;8(6):1018-25. https://doi.org/1 0.21037/jgo.2017.08.13.

32. Sada YH, Smaglo BG, Tan JC, Tran Cao HS, Musher BL, Massarweh NN Prognostic value of nodal response after preoperative treatment of gastric adenocarcinoma. J Natl Compr Cancer Netw. 2019;17(2):161-8. https://doi. org/10.6004/jnccn.2018.7093.

33. Viera AJ, Garrett JM. Understanding interobserver agreement: the kappa statistic. Fam Med. 2005;37(5):360-3.
34. Leake PA, et al. A systematic review of the accuracy and indications for diagnostic laparoscopy prior to curative-intent resection of gastric cancer. Gastric Cancer. 2012;15(Suppl 1):S38-47.

35. Gertsen EC, de Jongh C, Brenkman HJF, Mertens AC, Broeders IAMJ, Los M, et al. The additive value of restaging-CT during neoadjuvant chemotherapy for gastric cancer. Eur J Surg Oncol. 2020;46(7):1247-53. https://doi.org/10.1 016/j.ejso.2020.04.002.

36. Mazzei MA, et al. Gastric cancer maximum tumour diameter reduction rate at CT examination as a radiological index for predicting histopathological regression after neoadjuvant treatment: a multicentre GIRCG study. Gastroenterol Res Pract. 2018;2018:1794524.

\section{Publisher's Note}

Springer Nature remains neutral with regard to jurisdictional claims in published maps and institutional affiliations.
Ready to submit your research? Choose BMC and benefit from:

- fast, convenient online submission

- thorough peer review by experienced researchers in your field

- rapid publication on acceptance

- support for research data, including large and complex data types

- gold Open Access which fosters wider collaboration and increased citations

- maximum visibility for your research: over $100 \mathrm{M}$ website views per year

At BMC, research is always in progress.

Learn more biomedcentral.com/submissions 